\title{
Prevalence of Insufficient Sleep and Its Associated Factors Among Working Adults in Malaysia
}

\author{
Caryn Mei Hsien Chan (D) \\ Ching Sin Siau' \\ Jyh Eiin Wong $\mathbb{D}^{\prime}$ \\ Lei Hum Wee' \\ Nor Aini Jamil ${ }^{1}$ \\ Victor Chee Wai Hoe (ID) ${ }^{2}$ \\ 'Centre for Community Health Studies, \\ Faculty of Health Sciences, Universiti \\ Kebangsaan Malaysia, Kuala Lumpur, \\ Malaysia; ${ }^{2}$ Centre for Epidemiology and \\ Evidence-Based Practice, Department of \\ Social and Preventive Medicine, Faculty of \\ Medicine, University of Malaya, Kuala \\ Lumpur, Malaysia
}

Correspondence: Lei Hum Wee

Faculty of Health Sciences, Universiti Kebangsaan Malaysia, Jalan Raja Muda Abdul Aziz, Kuala Lumpur, 50300, Malaysia

Tel +60I $6309077 \mid$

Fax +60326938717

Email psychooncology.ukm@gmail.com
Introduction: Given the scarcity of data on sleep insufficiency in developing countries and its emerging importance in public health, this study aims to provide the prevalence and factors associated with insufficient sleep among working Malaysian adults.

Materials and Methods: A total of 11,356 working adults ( $\geq 18$ years) were recruited from a cross-sectional online health and work survey. Sleep duration was self-reported and was categorised as insufficient sleep $(<7 \mathrm{~h})$ and sufficient sleep $(\geq 7 \mathrm{~h})$ based on the National Sleep Guidelines' daily sleep time recommendation for adults. The 10-item Kessler scale was used to assess psychological distress levels (cutoff score $\geq 20$ ). Bivariate and multivariable regression analyses were performed to examine the factors associated with insufficient sleep.

Results: The mean age of the participants was 35.7 years (standard deviation, $\mathrm{SD} \pm 9.2$ ). There were more female $(\mathrm{n}=6613 ; 58.2 \%)$ respondents. The mean sleep duration was $6.49 \mathrm{~h}(\mathrm{SD} \pm 1.10)$. A total of 6212 individuals (54.7\%) reported getting $<7 \mathrm{~h}$ of sleep daily. After adjusting for gender, marital status and educational attainment, older age (odds ratio, $\mathrm{OR}=2.22,95 \%$ confidence interval, 95\% CI: $1.72-2.86)$, ever smoking ( $\mathrm{OR}=1.38,95 \% \mathrm{CI}: 1.25-1.53)$, and high psychological distress $(\mathrm{OR}=1.33$, 95\% CI: 1.17-1.53) were found to be associated with insufficient sleep. Factors associated with sleep duration of $<7 \mathrm{~h}$ per night included having children $(\mathrm{OR}=1.35,95 \% \mathrm{CI}$ : $1.21-1.50)$, lifestyle factors ( $\mathrm{OR}=1.38,95 \% \mathrm{CI}: 1.25-1.53)$, poor sleeping conditions $(\mathrm{OR}=1.21$, 95\% CI: 1.07-1.36), and mental health issues ( $\mathrm{OR}=1.32,95 \% \mathrm{CI}: 1.12-1.54)$.

Discussion and Conclusion: More than half of the participants reported sleep insufficiency. Older age, ever smoking, and high levels of psychological distress were significantly associated with insufficient sleep. Our findings recognise sleep as an emerging public health issue. Smoking cessation programmes and addressing high psychological distress may be beneficial to improve sleep.

Keywords: sleep, sleep deprivation, adults, ageing, psychological distress, smoking, Malaysia

\section{Introduction}

Insufficient sleep is gaining recognition as a public health concern, given emerging evidence on the consequential and modifiable nature of sleep. ${ }^{1}$ Chronic insufficient sleep is linked to poorer health outcomes, ${ }^{1,2}$ greater economic burden ${ }^{3,4}$ and as a contributor to health disparities. ${ }^{5}$

Most healthy adults aged 18 to 64 years require between seven and nine hours of sleep per night to function at their best. This recommended sleep time duration for adult individuals is backed by guidelines established by the American Academy of Sleep Medicine, ${ }^{6}$ the Sleep Research Society, ${ }^{6}$ and the National Sleep Foundation. ${ }^{7}$ 
It is unclear to what extent adults adhere to this recommendation. Regularly, even a single hour deficit in optimum sleep duration is associated with $60-80 \%$ higher odds of depression, hopelessness, nervousness, and restlessness. ${ }^{8}$ Current evidence indicate that weekday sleep debt cannot be overcome by compensatory measures such as sleeping in on weekends. ${ }^{9}$

Large-scale studies that have examined insufficient sleep among adults in the general population are mostly limited to those in developed countries. ${ }^{9-13}$ Thus, there is a need for evidence comprising samples from developing countries. While there is research on nationally representative samples in developed countries, sleep remains largely unsystematically explored in developing countries. ${ }^{9,10,14}$

Current studies on sleep from developing countries are limited to smaller samples targeting specific demographic groups. Specifically, sleep is often examined in older adults, ${ }^{15}$ individuals with comorbid illnesses, ${ }^{2}$ and different occupational sectors (eg, nurses, doctors, military, shift workers), ${ }^{16}$ as well as vulnerable subgroups such as those exposed to trauma.

Much of the available literature is also focused on clinical samples examining sleep disorders such as insomnia. However, the prevalence of non-disordered sleep is much less known. However, there are increasing evidence indicating that insufficient sleep syndrome should be recognised as a clinical entity. ${ }^{1,17}$ Even studies that had looked at insufficient sleep tend to focus on its effects and consequences. ${ }^{1,14}$ Currently, there is still a lack of evidence on the sociodemographic and modifiable risk factors that are associated with insufficient sleep among working adults in Malaysia.

There is a need to establish baseline data and greater epidemiological insight into factors associated with insufficient sleep in the Asia region. Data on sleep among working adults in Malaysia will allow us to better understand the extent of this public health burden. Identifying modifiable factors associated with insufficient sleep can help inform the development of appropriate interventions. Accordingly, the study aimed to determine the prevalence of insufficient sleep among adults and identify the factors associated with sleep insufficiency.

\section{Methods}

A cross-sectional survey was conducted in 2018 among 11,356 workers from 117 organisations in Malaysia. Participants were recruited through emails sent to their work email addresses. Participants were required to complete an anonymous online survey questionnaire. Their participation was entirely voluntary. This study adopted the same methodology as the first wave of the study conducted in 2017 and 2018, which has been described in full. ${ }^{18,19}$

Informed consent was obtained from participants before study commencement. Participants were informed beforehand that the data analysis would be based on a deidentified aggregated dataset. The de-identified aggregated data are available for organisational and academic research. It will not be available to the employer or for marketing purposes. The management of the data is compliant with the Malaysian Personal Data Protection Act 2010 and is regulated by the European Union's General Data Protection Regulation (GDPR) and UK Data Protection Act 2018. Ethical approval was obtained (JEP2019-692). This study was conducted in accordance with the Declaration of Helsinki.

\section{Sleep}

Participants self-reported their sleep duration based on the single-item question "On average, how many hours of sleep do you get in a 24-hour period?" Insufficient sleep was defined as rest/sleep of $<7 \mathrm{~h}$ per night on average over the past 30 days. Mean daily sleep time (in hours) for adult individuals was reported and categorised as inadequate sleep ( $<7 \mathrm{~h}$ of sleep) and adequate sleep ( $\geq 7 \mathrm{~h}$ of sleep). The categories were based on the American Academy of Sleep Medicine, the Sleep Research Society, and the National Sleep Foundation. ${ }^{6,7}$

\section{Psychological Distress}

The Kessler screening tool $(\mathrm{K} 10)^{20}$ was used to measure the presence and severity of non-specific psychological distress. The K10 scale consists of ten items assessing the frequency with which respondents experienced symptoms of psychological distress during the past 30 days. The response options range from 0 (none of the time) to 4 (all the time). The internal consistency was found to be acceptable. The scale has been translated and validated for use in this population. Participants' scores of $\geq 20$ were classified as high psychological distress. ${ }^{21}$

\section{Smoking}

Smoking was evaluated using a single-item question: "Do you smoke cigarettes?" Responses were as follows: No, I have never smoked cigarettes, No, but I used to smoke cigarettes, and I currently smoke cigarettes. Responses 
were classified according to ever smoking or never smoking status. Participants who indicated never having smoked cigarettes were considered never smokers, whereas individuals who reported previous or current use of cigarettes were designated as ever smokers.

\section{Lifestyle Factors}

Respondents were also asked about the factors that have affected their sleep quality, to which "yes/ no" responses were solicited. These factors were as follows: work stress, child/children, neighbours or housemates, lifestyle, financial concerns, health issues, relationship problems, poor sleeping conditions, and other mental health concerns (eg, depression).

\section{Statistical Analyses}

Data were assessed with IBM SPSS Statistics for Windows, Version 26.0 (IBM Corp., Armonk, N.Y., USA). We compared population characteristics, psychological distress, and smoking status by sleep group (sufficient vs insufficient sleep).

A multivariable logistic regression model was conducted to examine associations between insufficient sleep (dependent variable) and associated factors. The results are reported as crude and adjusted odds ratios (ORs) with 95\% confidence interval $(95 \% \mathrm{CI})$. To account for possible confounding, analyses were adjusted for age, gender, marital status, and educational attainment.

\section{Results}

Of 11,551 individuals who completed the survey, 195 $(1.7 \%)$ respondents who were non-Malaysians were excluded. Non-Malaysians were excluded due to the fact that their inclusion would likely influence statistical patterns and conclusions. This is because non-Malaysians may have different cultural backgrounds and face adjustment issues in Malaysia. ${ }^{22}$ These may serve as confounding variables which are not addressed in this study. A total of 11,356 adults were retained for analysis. Demographic, sleep, and mental health characteristics of the sample are shown in Table 1. The mean age of the participants was 35.7 (Standard Deviation, $\mathrm{SD} \pm 9.2$ ) years, there were more females $(n=6613 ; 58.2 \%)$ and the majority were married $(\mathrm{n}=6606 ; 58.2 \%)$. The mean sleep duration was $6.49 \mathrm{~h}$ (SD $\pm 1.10)$. A total of 6212 individuals $(54.7 \%)$ reported getting less than $7 \mathrm{~h}$ of sleep regularly. Long sleep duration (9 + hours) was excluded from analysis as the very low prevalence of long sleep $(n=72 ; 0.6 \%)$ did not allow for meaningful analysis. Using the K10, 1121 (9.9\%) had high levels of psychological distress (K10 scores $\geq 20$ ). In terms of smoking status, 8880 (78.2\%) were never smokers, whereas $2476(21.8 \%)$ were ever smokers (ex-smokers $\mathrm{n}=1220 ; 10.7 \%$ and current smokers $\mathrm{n}=1256 ; 11.1 \%$ ).

A sleep duration of $<7 \mathrm{~h}$ per night was associated with older age ( $\mathrm{OR}=2.22,95 \% \mathrm{CI}: 1.72-2.86$ ), ever smoking $(\mathrm{OR}=1.38,95 \% \mathrm{CI}: 1.25-1.53)$, and high psychological distress (OR=1.33, 95\% CI: 1.17-1.53) (Table 2). Other self-reported factors deemed by respondents to affect their sleep duration of $<7 \mathrm{~h}$ per night included having children ( $\mathrm{OR}=1.35, \quad 95 \% \quad \mathrm{CI}:$ 1.21-1.50), lifestyle factors ( $\mathrm{OR}=1.38,95 \% \mathrm{CI}: 1.25-1.53$ ), poor sleeping conditions $(\mathrm{OR}=1.21,95 \% \mathrm{CI}: 1.07-1.36)$, and other mental health concerns $(\mathrm{OR}=1.32,95 \% \mathrm{CI}: 1.12-1.54)$.

\section{Discussion}

\section{Main Findings of This Study}

This is the first large-scale study to estimate the prevalence of sleep insufficiency and its psychosocial determinants among working adults in Malaysia. We identified a high prevalence of insufficient sleep in this sample of working adults, with $54.7 \%$ of our sample reporting an average of $<7 \mathrm{~h}$ of sleep daily.

We found that insufficient sleep was associated with psychological distress, although it should be noted that only a small percentage $(9.87 \%)$ of respondents in this study reported psychological distress. Individuals with mental health issues had 1.32 times higher odds of insufficient sleep compared to those without psychiatric illness.

Our findings may be explained by numerous factors, particularly lifestyle, which can be adjusted. Many individuals have habits that make it difficult to get a good night's sleep.

There was an association between insufficient sleep and smoking, with workers who reported ever smoking having 1.38 times higher odds of insufficient sleep. In this sample, individuals who reported insufficient sleep also attributed it in part to the presence of children.

While we expected to see an age-related decrease in sleep duration, we were surprised to find that sleep insufficiency was an issue across most age brackets, starting from individuals $\geq 24$ years old. These odds increased with older age, with those in the 24-34 age bracket having 1.2 times higher odds of reporting sleep insufficiency, which increased to 1.5 for those 35-44 years, 1.9 for those $45-54$ 
Table I Characteristics of Malaysian Working Adults by Sleep Length $(\mathrm{N}=1 \mathrm{I}, 356)$

\begin{tabular}{|c|c|c|c|c|}
\hline & \multicolumn{2}{|c|}{ Sleep Duration } & \multirow{2}{*}{$\frac{\text { Overall Combined }}{n}$} & \multirow[t]{2}{*}{ p-value } \\
\hline & <7 Hours n (\%) & $\geq 7$ Hours n $(\%)$ & & \\
\hline $\begin{array}{l}\text { Age categories } \\
\text { 18-24 years } \\
25-34 \text { years } \\
35-44 \text { years } \\
45-54 \text { years } \\
55 \text { years and above }\end{array}$ & $\begin{array}{l}386(6.2) \\
2633(42.4) \\
1929(31.1) \\
991(16.0) \\
273(4.4)\end{array}$ & $\begin{array}{l}444(8.6) \\
2414(46.9) \\
1469(28.6) \\
654(12.7) \\
163(3.2)\end{array}$ & $\begin{array}{c}830 \\
5047 \\
3398 \\
1645 \\
436\end{array}$ & $0.00 I^{\mathrm{a}}$ \\
\hline $\begin{array}{l}\text { Gender } \\
\text { Male } \\
\text { Female }\end{array}$ & $\begin{array}{l}2662(42.9) \\
3550(57.1)\end{array}$ & $\begin{array}{l}208 \text { I (40.5) } \\
3063(59.5)\end{array}$ & $\begin{array}{l}4743 \\
6613\end{array}$ & $0.010^{\mathrm{b}}$ \\
\hline $\begin{array}{l}\text { Marital status } \\
\text { Cohabitating/Separated/Divorced/Widowed } \\
\text { Married } \\
\text { Single }\end{array}$ & $\begin{array}{c}319(5.1) \\
3724(59.9) \\
2169(34.9)\end{array}$ & $\begin{array}{c}201(3.9) \\
2882(56.0) \\
206 I(40.1)\end{array}$ & $\begin{array}{l}520 \\
6606 \\
4230\end{array}$ & $0.00 I^{\mathrm{a}}$ \\
\hline $\begin{array}{l}\text { Educational attainment } \\
\text { No formal education, primary, lower \& upper } \\
\text { secondary } \\
\text { A-levels or equivalent } \\
\text { Undergraduate degree } \\
\text { Postgraduate degree }\end{array}$ & $\begin{array}{l}866(13.9) \\
1411(22.7) \\
3067(49.4) \\
868(14.0)\end{array}$ & $\begin{array}{l}732(14.2) \\
1133(22.0) \\
2534(49.3) \\
745(14.5)\end{array}$ & $\begin{array}{l}1598 \\
2544 \\
5601 \\
1613\end{array}$ & $0.733^{\mathrm{a}}$ \\
\hline $\begin{array}{l}\text { Smoking status } \\
\text { Never smokers } \\
\text { Ever smokers }\end{array}$ & $\begin{array}{l}4703(75.7) \\
1509(24.3)\end{array}$ & $\begin{array}{c}4177(81.2) \\
967(18.8)\end{array}$ & $\begin{array}{l}8880 \\
2476\end{array}$ & $0.001^{b}$ \\
\hline $\begin{array}{l}\text { Psychological distress }^{c} \\
\text { KI0 score }<20 \\
\text { KI0 score } \geq 20\end{array}$ & $\begin{array}{c}5526(89.0) \\
686(11.0)\end{array}$ & $\begin{array}{c}4709 \text { (91.5) } \\
435(8.5)\end{array}$ & $\begin{array}{c}10,235 \\
|12|\end{array}$ & $0.001^{b}$ \\
\hline $\begin{array}{l}\text { Factors affecting sleep quality: } \\
\text { Work stress } \\
\text { Child/ children } \\
\text { Neighbours/ housing } \\
\text { Lifestyle } \\
\text { Financial concerns } \\
\text { Health issues } \\
\text { Relationship problems } \\
\text { Poor sleeping conditions } \\
\text { Mental health issues }\end{array}$ & $\begin{array}{c}2558(41.2) \\
1395(22.5) \\
229(3.7) \\
1272(20.5) \\
1162(18.7) \\
892(14.4) \\
761(12.3) \\
830(13.4) \\
547(8.8)\end{array}$ & $\begin{array}{c}1995(38.8) \\
940(18.3) \\
206(4.0) \\
828(16.1) \\
809(15.7) \\
700(13.6) \\
559(10.9) \\
568(11.0) \\
321(6.2)\end{array}$ & $\begin{array}{c}4553(40.1) \\
2335(20.6) \\
435(3.8) \\
2100(18.5) \\
1971(17.4) \\
1592(14.0) \\
1320(11.6) \\
1398(12.3) \\
868(7.6)\end{array}$ & $\begin{array}{l}0.100^{\mathrm{a}} \\
0.00 \mathrm{I}^{\mathrm{a}} \\
0.379^{\mathrm{a}} \\
0.00 \mathrm{I}^{\mathrm{a}} \\
0.00 \mathrm{I}^{\mathrm{a}} \\
0.25 \mathrm{I}^{\mathrm{a}} \\
0.02 \mathrm{I}^{\mathrm{a}} \\
0.00 \mathrm{I}^{\mathrm{a}} \\
0.00 \mathrm{I}^{\mathrm{a}}\end{array}$ \\
\hline
\end{tabular}

Notes: Percentages are based on column. For factors affecting sleep quality, participants selected all drop-down options that applied, with these numbers and percentages,

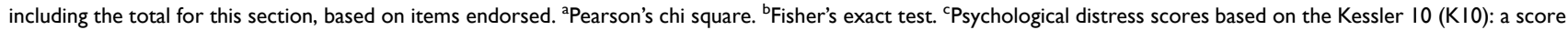
of $\geq 20$ indicates the presence of psychological distress.

years, and 2.2 for those aged $\geq 55$ years as compared to those in the 18-24 age bracket.

\section{What is Already Known}

The rate of sleep insufficiency in this sample is much higher in comparison with the United States and Australia, with the prevalence rates of $34.8 \%{ }^{2}$ and
$24.0 \%,{ }^{23}$ respectively. Previous data from Malaysia tend to focus on specific subpopulations $s^{24-26}$ and clinically diagnosed sleep disorders, ${ }^{27}$ albeit we do not discount the fact that individuals who report insufficient sleep are much more likely to have a sleeping disorder. This study, therefore, addresses a gap in the literature on the extent of insufficient sleep among working adults in Malaysia. 
Table 2 Multivariable Logistic Regression of Factors Associated with Insufficient Sleep Among Working Adults in Malaysia $(\mathrm{N}=11,356)$

\begin{tabular}{|c|c|c|c|}
\hline & \multicolumn{3}{|c|}{ Adjusted } \\
\hline & Odds Ratio & $95 \% \mathrm{Cl}$ & p-value \\
\hline \multicolumn{4}{|l|}{ Age categories } \\
\hline 18-24 years (ref) & - & - & - \\
\hline $25-34$ years & 1.21 & $1.03-1.41$ & 0.017 \\
\hline $35-44$ years & 1.50 & $1.26-1.77$ & 0.001 \\
\hline $45-54$ years & 1.88 & $1.56-2.27$ & 0.001 \\
\hline 55 years and above & 2.22 & $1.72-2.86$ & 0.001 \\
\hline \multicolumn{4}{|l|}{ Gender } \\
\hline Male (ref) & - & - & - \\
\hline Female & 1.05 & $0.96-1.14$ & 0.298 \\
\hline \multicolumn{4}{|l|}{ Marital status } \\
\hline Cohabitating/Separated/Divorced/Widowed (ref) & - & - & - \\
\hline Married & 0.82 & $0.68-0.99$ & 0.039 \\
\hline Single & 0.80 & $0.65-0.97$ & 0.024 \\
\hline Educational attainment & & & 0.132 \\
\hline No formal education, primary, lower \& upper secondary & - & - & - \\
\hline A-levels or equivalent & 1.10 & $0.97-1.25$ & 0.156 \\
\hline Undergraduate degree & 1.13 & $1.01-1.28$ & 0.042 \\
\hline Postgraduate degree & 1.03 & $0.89-1.19$ & 0.678 \\
\hline \multicolumn{4}{|l|}{ Smoking status } \\
\hline Never smokers (ref) & - & - & - \\
\hline Ever smokers & 1.38 & $1.25-1.53$ & 0.001 \\
\hline \multicolumn{4}{|l|}{ Psychological distress } \\
\hline KIO score less than 20 (ref) & - & - & - \\
\hline KIO psychologically distressed score $\geq 20$ & 1.33 & $1.17-1.53$ & 0.001 \\
\hline \multicolumn{4}{|l|}{ Factors affecting sleep quality: } \\
\hline Work stress & 1.02 & $0.94-1.10$ & 0.701 \\
\hline Child/ children & 1.35 & $1.21-1.50$ & 0.001 \\
\hline Neighbours/ housing & 0.89 & $0.7 I-1.06$ & 0.163 \\
\hline Lifestyle & 1.38 & $1.25-1.53$ & 0.001 \\
\hline Financial concerns & 1.12 & $1.01-1.25$ & 0.040 \\
\hline Health issues & 0.92 & $0.82-1.03$ & 0.149 \\
\hline Relationship problems & 1.03 & $0.91-1.17$ & 0.632 \\
\hline Poor sleeping conditions & 1.21 & $1.07-1.36$ & 0.002 \\
\hline Mental health issues & 1.32 & $1.12-1.54$ & 0.001 \\
\hline
\end{tabular}

Note: DV: Sleep, less than 7 hours of sleep.

At least one previous study has found mildly insufficient sleep to be associated with symptoms of anxiety and depression. ${ }^{8}$ Our findings concerning smoking and insufficient sleep are consistent with findings from other studies which reported that sleep-deprived individuals tend to smoke and have caffeinated drinks two hours before bedtime. ${ }^{28,29}$

Our findings differ from past evidence that young adults are more vulnerable to chronic sleep deficiency and recurrent circadian disruption than older adults, ${ }^{30}$ and are at odds with reports which indicate that older adults are less likely to experience issues related to sleep. ${ }^{22}$

The presence of children has been found to be a risk factor for insufficient sleep among adults. ${ }^{31}$ A study in Singapore found that adults who slept with children, studied, read leisurely, drank caffeinated beverages or smoked were more likely to experience inadequate sleep. ${ }^{29}$ Individuals who reported insufficient sleep were also far more likely to tend to use mobile devices in bed or 
in the bedroom. ${ }^{29}$ At least one past study has listed neighbours as a reason for insufficient sleep, as poorer neighbourhoods may be less conducive environmentally for sleep. ${ }^{32}$ In tandem with the lack of evidence in this regard, neighbourhood factors were found not significant factors for insufficient sleep in our study.

Existing research suggests that older age, female gender, comorbidities, and high distress are risk factors for insufficient sleep. ${ }^{1}$ Consistent with previous studies, age, high psychological distress, and smoking were significantly associated with insufficient sleep in this study. Unfortunately, we cannot clarify the order of precedence for either outcome or predictor, given the cross-sectional nature of this study. Insufficient sleep may be a precursor to mental health issues, although this potential bidirectionality cannot be established in this study. It is also possible that the numerous risk factors known to be associated with insufficient sleep are buffered by other protective factors not considered in this study.

\section{What This Study Adds}

These findings are important as they will allow us to identify sleep as a potential public health priority. Based on these findings, the researchers plan to further explore lifestyle factors for inadequate sleep and develop a checklist for working adults who experience sleep-related problems. This will likely prove beneficial in identifying modifiable factors which can be targeted for intervention among individuals with insufficient sleep, eg, eliminating consumption of caffeinated beverages before bedtime. Napping could be implemented in the workplace to counter short sleep duration, as it has been found to reduce coronary mortality, improve cognition, and improve immune functions (see Faraut et $\mathrm{al}^{33}$ for a clinical review).

Future research needs to be devoted to continued research with samples from developing countries, and should include more diverse samples concerning participant age, health status (ie, presence of comorbid illness), gender, and ethnicity with increased cross-cultural research. Working to explore the psychological mediators of sleep is also essential. Future research is needed to examine longitudinal relationships between sleep and mental health prospectively. Respite interventions have been found to help employees replenish and build energy resources at work. ${ }^{34}$ Several meta-analyses have found strong evidence of a beneficial effect of respite interventions on sleep and mental health. ${ }^{35-36}$ This study offers evidence of the actual rate of sleep issues in the working population in Malaysia and suggests a need for further study.

Our findings contribute to a greater understanding of the impact that psychosocial factors have on health and psychological well-being, and carry implications for mental and physical well-being, as sleep influences both mental and physical health. In terms of policy, findings in this study can help researchers, clinicians, and public health policymakers gain a better understanding of insufficient sleep, especially its risk and protective factors in Malaysia. More systematic and empirically stringent methodologies and research frameworks need to be used, however. A holistic approach for the planning of preventative strategies and public health policies should be made according to these risk factors.

\section{Limitations}

Among the limitations of this study is that a validated measure of sleep was not used. It is also unclear to what extent sleep insufficiency represents overall psychological well-being. Furthermore, we focused on insufficient sleep duration and not on sleep quality. Past studies using moderator analyses indicate that relationships between sleep quality and quantity may be affected by measurement method and the number of self-reported items used, while there is little evidence of the effect of measurement time frame. ${ }^{34}$ No causality can be determined due to the cross-sectional nature of our study. It is unclear to what extent the various factors tested here are bidirectionally associated with sleep. The sample is not nationally representative due to the use of non-probability sampling approach in this study. The exact participation rate for the study is impossible to estimate because we cannot determine the number of employees who actually received or read the invitation email as only de-identified aggregated data were available for analysis. We did not check for the possible occurrence of multiple entries from the same individual (eg, through cookies used, IP check and $\log$ file analysis). We were unable to provide useful information that helps interpret the working population or the industries involved in this study. Also, because the samples were self-selected, these results have to be interpreted with caution.

\section{Conclusion}

The good news is that sleep is a malleable behaviour that can be improved by individual and organisational changes. Findings underscore the need for further study to 
determine the complex links and factors that can be identified for intervention via programs to inform comprehensive policies taking sleep into account among public health challenges in this setting, as a public health priority.

\section{Data Sharing Statement}

Due to confidentiality agreements with research collaborators, the data that support the findings of this study cannot be made publicly available online. Restrictions apply to the availability of these data, which were used by researchers subject to a non-disclosure agreement for this study. Requests to access the data may be sought from RAND Europe with the permission of AIA Malaysia.

\section{Ethics}

Electronic informed consent was completed by participants before study commencement. Ethical approval was obtained from Universiti Kebangsaan Malaysia (JEP2019-692). This study was conducted in accordance with the Declaration of Helsinki.

\section{Acknowledgments}

This work was supported by the Universiti Kebangsaan Malaysia Grants No. NN-2018-168 and NN-2018-148.

\section{Author Contributions}

CMHC, CSS, WJE, LHW, NAJ participated in the study conception, design, and coordination of the manuscript. CMHC performed statistical analysis and drafted the earliest iterations of the manuscript. VCWH revised multiple versions of the manuscript and contributed significant intellectual content. All authors contributed to data analysis, drafting or revising the article, have agreed on the journal to which the article will be submitted, gave final approval of the version to be published, and agree to be accountable for all aspects of the work.

\section{Funding}

This work was supported by the Universiti Kebangsaan Malaysia, Grants No. NN-2018-168 and NN-2018-148, which played no role or involvement in any of the stages from study design to submission of the paper for publication.

\section{Disclosure}

The authors report no conflicts of interest in this work.

\section{References}

1. Chattu V, Manzar MD, Kumary S, Burman D, Spence D, PandiPerumal S. The global problem of insufficient sleep and its serious public health implications. Healthcare. 2019;7(1):1. doi:10.3390/ healthcare7010001

2. Liu Y, Wheaton AG, Chapman DP, Cunningham TJ, Lu H, Croft JB. Prevalence of healthy sleep duration among adults - United States, 2014. MMWR Morb Mortal Wkly Rep. 2016;65(6):137-141. doi:10.15585/mmwr.mm6506a1

3. Hafner M, Stepanek M, Taylor J, Troxel WM, Van Stolk C. Why sleep matters: the economic costs of insufficient sleep. Rand Health Q. 2017;6(4):11.

4. Hillman D, Mitchell S, Streatfeild J, Burns C, Bruck D, Pezzullo L. The economic cost of inadequate sleep. Sleep. 2018;41(8):zsy083. doi:10.1093/sleep/zsy083

5. Laposky AD, Van Cauter E, Diez-Roux AV. Reducing health disparities: the role of sleep deficiency and sleep disorders. Sleep Med. 2016;18:3-6. doi:10.1016/j.sleep.2015.01.007

6. Watson NF, Badr MS, Belenky G, et al. Recommended amount of sleep for a healthy adult: a joint consensus statement of the American academy of sleep medicine and sleep research society. Sleep. 2015;38 (6):843-844.

7. Hirshkowitz M, Whiton K, Albert SM, et al. National sleep foundation's sleep time duration recommendations: methodology and results summary. Sleep Health. 2015;1(1):40-43. doi:10.1016/j. sleh.2014.12.010

8. Sullivan K, Ordiah C. Association of mildly insufficient sleep with symptoms of anxiety and depression. Neurol Psychiatry Brain Res. 2018;30:1-4. doi:10.1016/j.npbr.2018.03.001

9. Chami HA, Ghandour B, Isma'eel H, Nasreddine L, Nasrallah M, Tamim H. Sleepless in Beirut: sleep duration and associated subjective sleep insufficiency, daytime fatigue, and sleep debt in an urban environment. Sleep Breath. 2019;27:1.

10. Bhatta N, Kattel V, Bhatta N. Study of sleep habits and patterns across various age groups: an exploratory study from developing country. Am J Respir Crit Care Med. 2018;197:a7294.

11. Grandner MA, Smith TE, Jackson N, Jackson T, Burgard S, Branas C. Geographic distribution of insufficient sleep across the United States: a county-level hotspot analysis. Sleep Health. 2015;1 (3):158-165. doi:10.1016/j.sleh.2015.06.003

12. Morita Y, Sasai-Sakuma T, Asaoka S, Inoue Y. Prevalence and correlates of insufficient sleep syndrome in Japanese young adults: a Web-Based Cross-Sectional Study. J Clin Sleep Med. 2015;11 (10):1163-1169. doi:10.5664/jcsm.5092

13. Varghese NE, Lugo A, Ghislandi S, Colombo P, Pacifici R, Gallus S. Sleep dissatisfaction and insufficient sleep duration in the Italian population. Sci Rep. 2020;10(1):17943. doi:10.1038/s41598-020$72612-4$

14. Wang C, Bangdiwala SI, Rangarajan S, et al. Association of estimated sleep duration and naps with mortality and cardiovascular events: a study of 116,632 people from 21 countries. Eur Heart J. 2019;40(20):1620-1629. doi:10.1093/eurheartj/ehy695

15. Dzierzewski JM, Dautovich ND. Who cares about sleep in older adults? Clin Gerontol. 2018;41(2):109-112. doi:10.1080/ 07317115.2017.1421870

16. Kecklund G, Axelsson J. Health consequences of shift work and insufficient sleep. BMJ. 2016;355:i5210. doi:10.1136/bmj.i5210

17. Kohyama J, Anzai Y, Ono M, et al. Insufficient sleep syndrome: an unrecognized but important clinical entity. Pediatr Int. 2018;60 (4):372-375. doi:10.1111/ped.13519

18. Chan CMH, Wong JE, Yeap LL, Wee LH, Jamil NA, Nantha YS. Workplace bullying and psychological distress of employees across socioeconomic strata: a Cross-Sectional Study. BMC Public Health. 2019;19(4):1-8. doi:10.1186/s12889-019-6859-1 
19. Chan CMH, Ng SL, In S, Wee LH, Siau CS. Predictors of psychological distress and mental health resource utilization among employees in Malaysia. Int J Environ Res Public Health. 2021;18(1):314. doi:10.3390/ijerph18010314

20. Kessler RC, Andrews G, Colpe LJ, et al. Short screening scales to monitor population prevalences and trends in non-specific psychological distress. Psychol Med. 2002;32(6):959-976. doi:10.1017/ S0033291702006074

21. Tiong XT, Abdullah NS, Bujang MA, et al. Validation of the kessler's psychological distress scale (k10 \& k6) in a Malaysian population. Asian J Psychiatr. 2018;19(1).

22. Richardson C, Tan GH, Kiumarsi S. Personality traits and expatriate adjustment in Malaysia. J Asia Bus Stud. 2018;12(4):594-612. doi:10.1108/JABS-06-2017-0091

23. Gordon S, Vandelanotte C, Rayward AT, Murawski B, Duncan MJ. Sociodemographic and behavioral correlates of insufficient sleep in Australian adults. Sleep Health. 2019;5(1):12-17. doi:10.1016/j. sleh.2018.06.002

24. Fauzi MF, Yusoff HM, Abd Manaf MR, et al. Intervention for occupational fatigue and sleepiness among healthcare workers working in shift: a systematic review. Malaysian J Public Health Med. 2019;19(2):47-53. doi:10.37268/mjphm/vol.19/no.2/art.170

25. Razali R, Ariffin J, Aziz AF, Puteh SE, Wahab S, Daud TI. Sleep quality and psychosocial correlates among elderly attendees of an urban primary care centre in Malaysia. Neurol Asia. 2016;21(3).

26. Sazlina SG, Chan YM, Hamid TA, Suzana S, Singh DK. Associations between falls and psychosocial factors, self-rated health, disability and sleep among community dwelling older people in Malaysia. J Clin Gerontol Geriatr. 2018;9(3):85-90.

27. Firouzi S, Bee Koon P, Noor MI, Sadeghilar A. Sleep pattern and sleep disorders among a sample of Malaysian children. Sleep Biol Rhythms. 2013;11(3):185-193. doi:10.1111/sbr.12020

28. Costa M, Esteves M. Cigarette smoking and sleep disturbance. Addict Disord Their Treat. 2018;17(1):40-48. doi:10.1097/ADT.0000000 000000123
29. Tan NC, Tan MS, Hwang SW, et al. Sleep time and pattern of adult individuals in primary care in an Asian urbanized community: a Cross-Sectional Study. Medicine. 2016;95:35. doi:10.1097/ MD.0000000000004749

30. Zitting KM, Münch MY, Cain SW, et al. Young adults are more vulnerable to chronic sleep deficiency and recurrent circadian disruption than older adults. Sci Rep. 2018;8(1):1-4. doi:10.1038/s41598018-29358-X

31. Chapman DP, Wheaton AG, Perry GS, Sturgis SL, Strine TW, Croft JB. Household demographics and perceived insufficient sleep among US adults. J Community Health. 2012;37(2):344-349. doi:10.1007/s10900-011-9451-x

32. Simonelli G, Dudley KA, Weng J, et al. Neighborhood factors as predictors of poor sleep in the Sueno ancillary study of the Hispanic Community Health Study/Study of Latinos. Sleep. 2017;40(1): zsw025. doi:10.1093/sleep/zsw025

33. Faraut B, Andrillon T, Vecchierini MF, Leger D. Napping: a public health issue. From epidemiological to laboratory studies. Sleep Med Rev. 2017;35:85-100. doi:10.1016/j.smrv.2016.09.002

34. Steidle A, Gonzalez-Morales MG, Hoppe A, Michel A, O'shea D. Energizing respites from work: a randomized controlled study on respite interventions. Eur $J$ Work Organ Psychol. 2017;26 (5):650-662. doi:10.1080/1359432X.2017.1348348

35. Torquati L, Mielke GI, Brown WJ, Burton NW, Kolbe-Alexander TL. Shift work and poor mental health: a meta-analysis of longitudinal studies. Am J Public Health. 2019;109(11):e13-20. doi:10.2105/ AJPH.2019.305278

36. Litwiller B, Snyder LA, Taylor WD, Steele LM. The relationship between sleep and work: a meta-analysis. J Appl Psychol. 2017;102 (4):682. doi:10.1037/ap10000169

\section{Publish your work in this journal}

Nature and Science of Sleep is an international, peer-reviewed, open access journal covering all aspects of sleep science and sleep medicine, including the neurophysiology and functions of sleep, the genetics of sleep, sleep and society, biological rhythms, dreaming, sleep disorders and therapy, and strategies to optimize healthy sleep.
The manuscript management system is completely online and includes a very quick and fair peer-review system, which is all easy to use. Visit http://www.dovepress.com/testimonials.php to read real quotes from published authors. 